\title{
Bauru School of Dentistry Tele-Health League: an educational strategy applied to research, teaching and extension among applications in tele-health
}

\author{
Andressa Sharllene Carneiro da SILVA ${ }^{1}$, Fabio Antonio Piola RIZZANTE ${ }^{2}$, Mirela Machado PICOLINI ${ }^{3}$, Karis de \\ CAMPOS $^{3}$, Camila de Castro CORRÊA ${ }^{4}$, Elen Caroline FRANCO ${ }^{5}$, Cássia de Souza PARDO-FANTON ${ }^{6}$, Wanderléia \\ Quinhoneiro BLASCA7 , Giédre BERRETIN-FELIX ${ }^{8}$
}

\begin{abstract}
1-President of the Tele-Health League of Bauru School of Dentistry, Sciences of Rehabilitation Masters' student, Hospital of Rehabilitation of Craniofacial Anomalies, University of São Paulo, Bauru, SP, Brazil.

2- Head secretary of the Tele-Health League of Bauru School of Dentistry, Undergraduate student, Bauru School of Dentistry, University of São Paulo, Bauru, SP, Brazil. 3- Member of the Tele-Health League of Bauru School of Dentistry, Masters student, Department of Speech-Language Pathology and Audiology, Bauru School of Dentistry, University of São Paulo, Bauru, SP, Brazil.

4- BS, Speech-Language Pathologist, Department of Speech-Language Pathology and Audiology, Bauru School of Dentistry, University of São Paulo, Bauru, SP, Brazil. 5- Head treasure of the Tele-Health League of Bauru School of Dentistry, Masters student, Department of Speech-Language Pathology and Audiology, Bauru School of Dentistry, University of São Paulo, Bauru, SP, Brazil.

6- BS in Translation, Universidade Sagrado Coração - USC; Masters student, Department of Speech-Language Pathology and Audiology, Bauru School of Dentistry, University of São Paulo, Bauru, SP, Brazil.

7- BS, MS, PhD, Assistant Professor, Department of Speech-Language Pathology and Audiology; Coordinator Professor of the Tele-Health League of Bauru School of Dentistry, Coordinator Professor of the Young Doctor Project, Bauru School of Dentistry, University of São Paulo, Bauru, SP, Brazil.

8- BS, MS, PhD, Associate Professor, Department of Speech-Language Pathology and Audiology; Tutor of the Tutorial Education Program in Speech-Language Pathology and Audiology, Vice-Coordinator of the Tele-Health League of the Bauru School of Dentistry, University of São Paulo, Bauru, SP, Brazil.
\end{abstract}

Corresponding address: Andressa Sharllene Carneiro da Silva - Rua Doutor José Maria Rodrigues Costa, 4-30 - 17017331 - Bauru - SP - Brazil - Phone: +55 1497718007 - e-mail: fga.asc@gmail.com/ asc@usp.br

Received: July 24, 2010 - Accepted: September 15, 2011

\section{ABSTRACT}

T ele-health is more than an innovative alternative; it is an excellent tool that enables access to health and education in health, making it possible to minimize distances, optimize time and reduce costs. Based on these advantages, some Brazilian Universities have used these actions in strategies of education, research and extension, aiming at the application of Tele-health in Brazil. In that way, the Bauru School of Dentistry - University of São Paulo (FOB-USP) has applied the use of information and communication technologies in health by means of a "Tele-Health League" (TL), in order to diagnose, prevent and treat diseases, in addition to educate the population and health services. Objective: The present study aims to introduce the characteristics of the Tele-Health League of FOB-USP, as well as the development of its projects. Material and Methods: The Tele-Health League consisted as a Diffusion Course approved by the Provost of Culture and Academic Extension of the University of São Paulo. It is composed as a large group enclosing professoriate coordinator, academician principal, contributing professors and league members, those, diversified between undergraduates students, graduated, health employees, technology and information areas. The participant members are evaluated by the presence frequency (minimum of $85 \%$ ), and by the performance of tests and paperwork about the theoretical content provided. Results: In four years of activities, the TLFOB-USP obtained a high satisfaction index (90\%), an increased number of vacancies due to the interest to become a member, more commitment of the professors of the University and the accomplishment of association with other Brazilian leagues. It is emphasized that the approval percentage of the course results in approval from approximately half of its members. Also, it is important to identify and repair the causes related to the quitting of some members. Conclusions: The results showed that the TLFOB-USP members, adjoining to the professor's participants, develop projects in Tele-helth, in Tele-aid and Tele-education areas, thus resulting in the involvement of the University and the community.

Key words: Distance education. Telemedicine. Interdisciplinary communication. 


\section{INTRODUCTION}

Based on the distribution and education heterogeneity of the professionals of the health area on the different regions of the country, the broad extension of the Brazilian territory, the irregular distribution of doctors and specialists, as well as the diversity of the quality and availability of health services in the country, recent studies ${ }^{5,14-16,20,27-28}$ have focused on the urgent need to develop in Brazil proposals that enable the utilization of Telemedicine in several areas of health.

Telemedicine, in its broad concept Telehealth ${ }^{1,21-23,25}$, enables continued education, which enables educating health professionals, despite location and distance, to contribute to a better interdisciplinary and overall expansion of knowledge 29 .

However, as more than an innovative alternative, Tele-health is configured as an excellent tool capable to allow the access to health in deprived populations, enhance life conditions of the Brazilian population ${ }^{2,13,19}$, minimize the distances and offer assistance services and permanent education to empower the principles of the Brazilian National Health System (Sistema Único de Saúde SUS): universality, equality, justice, integrality, decentralization and social participation ${ }^{10}$.

The concepts and techniques of Distance Education and Tele-education, conceptualized as one of the sides of Tele-health applied to research, education and extension are rapidly developing in all areas of knowledge, mainly in the area of health ${ }^{4,11-12,24,29}$. It represents a deeply cultural and work practice change that must bring improvement for all health professionals.

Currently, the undertaking in educational programs on Tele-health, its technologies assistance and the modern options of graphic designs, have changed considerably the interaction of schools and its students, researches and community $3,6,8,17$ (Figure 1), which makes it possible to obtain higher levels of communication 8,13,17,24. As result of this information, the distance stopped being a highly critical factor to the assistance of health professionals and the application of education, mainly in isolated areas ${ }^{2}$. Thus, it is possible to exchange knowledge between professionals and improve the assistance to the patients and their community ${ }^{6-7}$.

According to the increasing demand of the applications of information technologies and communication in the health service it is a tendency that, in the near future, it will be necessary for professionals to have broad knowledge of these technologies. Thus, Tele-health promotes to the students the experience shared with multiple Universities, Schools and communities as an essential and advanced part of their process apprenticeship 9 . The moment of education of the student in graduation and post graduation is crucial.

In this perspective, some Brazilian Universities such as the University of São Paulo, the Federal University of São Paulo, the State University of Campinas, and the Federal University of Rio Grande do Sul and the Federal University of Pernambuco, have taken action to disseminate Tele-Health in Brazil ${ }^{9,26}$.

The Bauru School of Dentistry of the University of São Paulo (FOB-USP) pursued enabling the information technologies and the communication that allows the diagnose, the prevention and the treatment of diseases, beyond the education of the population and the health services by means of the "Tele-Health League of the FOB-USP" (TLFOB-USP) that is recognized as an Academic Extension Course,

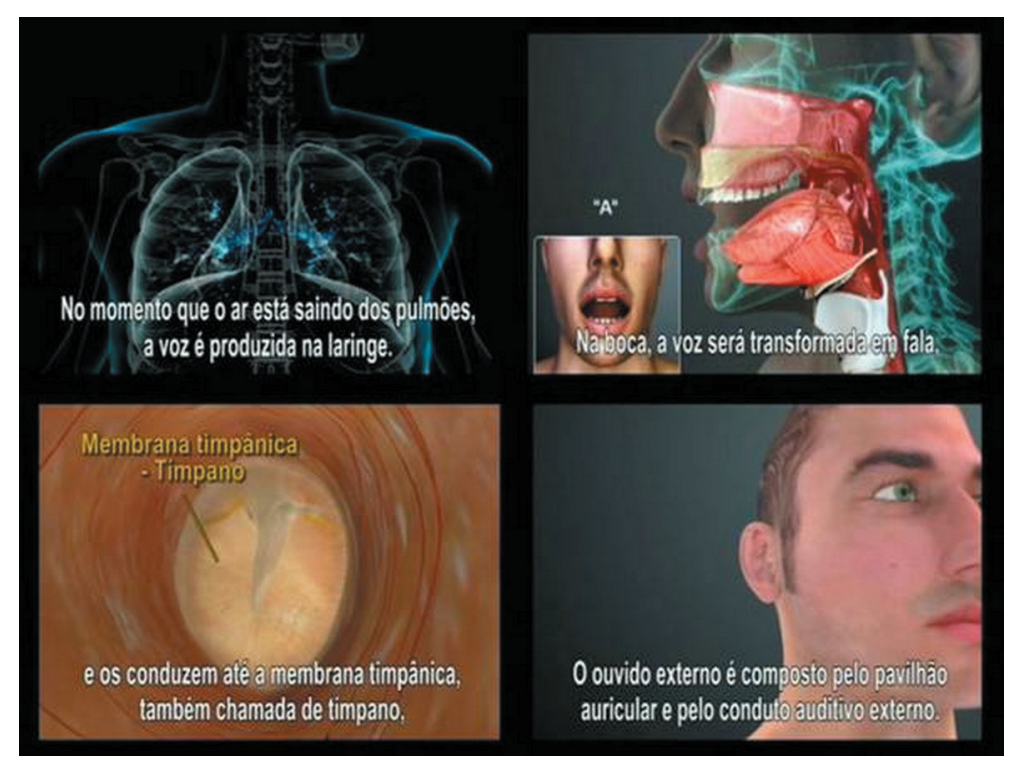

Figure 1- Study Object, CD-ROM Virtual Man Voice Assessment and Virtual Man Hearing Assessment 
properly approved by the Provost of Culture and Academic Extension of the University of São Paulo, as a Diffusion course.

\section{OBJECTIVES}

The present study aims to introduce the characteristics of the Tele-health League of FOBUSP, as well as the development of its projects.

\section{MATERIAL AND METHODS}

The TLFOB-USP was founded in 2007 as an initiative of the Tutorial Education Program (PET) in Speech-Language Pathology and Audiology; it was the main proposal of the program. The TLFOB-USP formed the program in an interdisciplinary manner based on the Tele-aid and Tele-education actions, to make it capable to be applied, mainly, in SpeechLanguage Pathology and Audiology and Dentistry.

Nowadays, it is composed of 100 components, titled "League Members," which are being constituted by an academic student board of graduate and post-

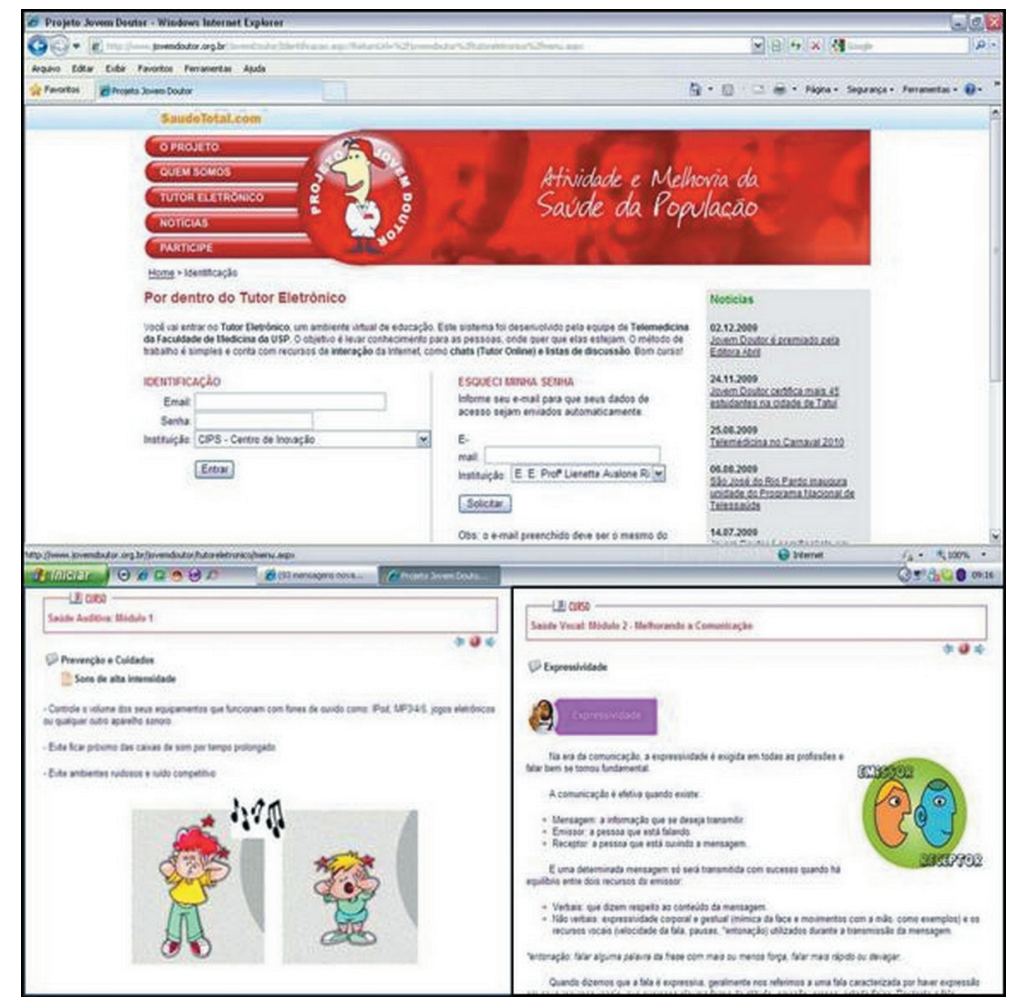

Figure 2- Virtual learning environment (Cybertutor) used in the Young Doctor Project

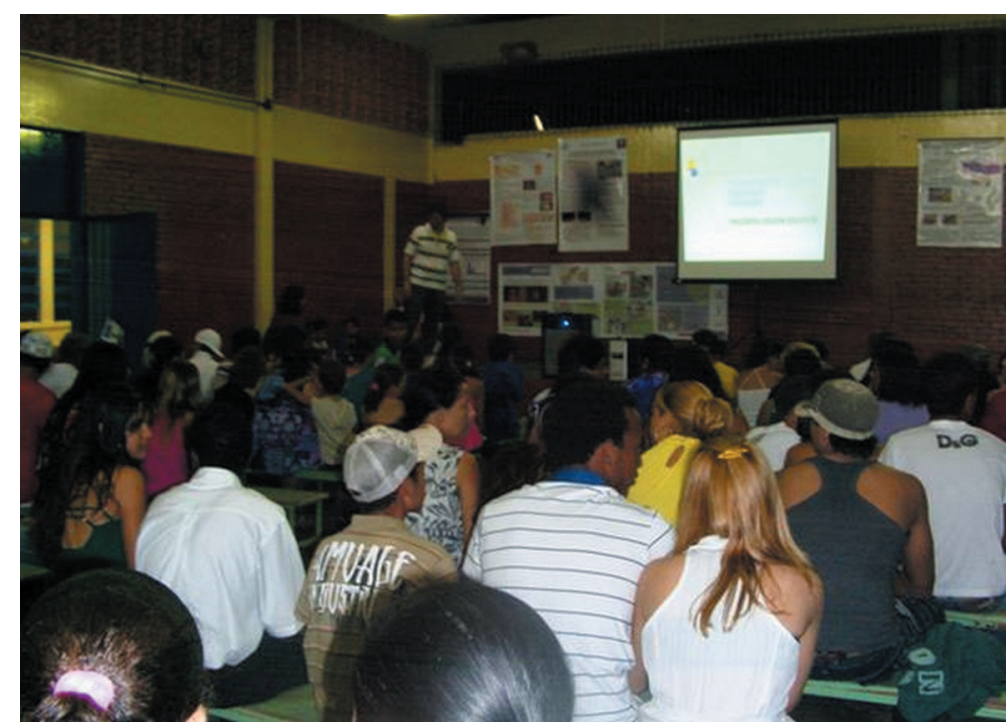

Figure 3- Production chain in health, knowledge and value hierarchy of the university to the community 
graduate students on the positions of chairman, head treasurer and head secretary; a professor board of a professor coordinator and one substitute; a professor advisory of 20 professors; assistance committee subdivided into a publicizing committee, human resources committee and scientific and projects committee of 24 graduation academics, as well as scholars of the Tutorial Education Program (PET) of the Speech-Language Pathology and Audiology and Dentistry courses.

Therefore, the TLFOB-USP spans the graduate and post-graduate courses, professors and employees of the Bauru School of Dentistry - FOBUSP, the post-graduation courses and the internship of the Hospital for Rehabilitation of Craniofacial Anomalies (HRAC). The selection of the participants is achieved every year at the first semester by the means of the application of a test after the presentation of an introductory course.

The TLFOB-USP has specific goals: 1 ) to develop and publish scientific studies in Tele-health conducted by the coordinators; 2) to organize monthly meetings in which lectures, seminars, panel discussions and workshops are given by professors and/or by professionals or the League members; 3) to accomplish the distance activities settled by the tutoring of the professors involved; 4 ) to conduct the actions of Tele-aid implemented at the Campus of Bauru of the University of São Paulo; 5) to facilitate the implementation of distance education in the units assisted by FOB-USP, and 6) to support the projects developed by its Tele-health group in an interdisciplinary approach.

\section{RESULTS AND DISCUSSION}

Presence and distance activities were performed following a programmatic content proposed yearly. Specific themes included basic and advanced informatics applied to health; innovations related to communication; interactive Tele-education; Tele-aid and second formative opinion; advanced seminars; Tele-health to support Health Politics and Education in Brazil, completing a 120hour workload. The participants are constantly evaluated in all activities proposed by an evaluation of their performance considering the criteria: assiduousness; relationship with the professors, colleagues and patients; punctuality; personal presentation and commitment. Moreover, the participants are evaluated by tests about the theoretical content given and by the presentation of written papers developed in workshops. At the end of the process, the approved members of the Extension Course of TLFOB-USP receive a certificate of approval and conclusion given by the Provost of Culture and Academic Extension of the University of São Paulo.
The acquisition of knowledge may be performed in different ways, such as presence and by distance. Moreover, distance education is becoming more recognized by its countless benefits such as rapid information access, speedy updating, supervised apprenticeship, flexibility with the research, and availability of tools, as well as the advances in technology communication and information ${ }^{18}$; it is expected that the members of the TLOB-USP will have complete formation and access to presence and distance activities at the end of the course, with innovative experiences from the development of projects in Tele-health, since such activities have increased considerably and the perspective that it enables a globalization of the health knowledge ${ }^{15}$.

In this way, the member participants of the League have developed, jointly to its professors, activities that comprised research, teaching and extension projects in Tele-health. For example, projects have included "Babies Portal", "The Virtual Man - Hearing Assessment", "The Virtual Man Personal Sound Amplifier", "The Young Doctor Project", "Distance Capacitating Courses", "CD and DVD development - orientations to health patients and professionals", and "Capacitation of Health Community Agents and Participation in the Tele-health Program of the São Paulo Division" (Figure 2).

Thus, the projects developed by TLFOBUSP, mainly in Speech-Language Pathology and Audiology, are real examples of the application in Tele-education and Tele-aid.

The development and achievement of the projects and programs in Tele-education accomplished by the TLFOB-USP introduces the principal characteristic of "Hierarchy of the knowledge" (Figure 3). This proposal characterizes the formation of a productive health chain, in which every individual is important in achieving a global project. The goal is to prevent diseases and facilitate social reintegration of people that possess disease ${ }^{6}$. The focus is mainly those diseases that result in communication disorders, such as hearing impairment, malformation, trauma, and others.

In this perspective of Distance Education and Interactive Tele-education, the members of the League, professor coordinators, and the community created a collaborative network of apprenticeship in health.

In conclusion, it is important to highlight that in four years of activities of the TLFOB-USP has achieved good results in an increasing and satisfactory manner; the interest to improve enlarged the number of positions from 72 to 100 . It is also emphasized that a higher involvement of the professors of the FOB-USP occurs as well as the association with other institutions by means of the Telemedicine and Tele-health Leagues all over 
the country.

Overall, it is verified that the occurrence of a high satisfaction index of the activities offered by TLFOB-USP over these years is an average of $90 \%$. Nevertheless, the percentage of members approved at the end of the course has resulted in approximately $50 \%$ of the total of the participants; a minimum presence frequency of $85 \%$ sum to achieve distance activities is necessary.

\section{CONCLUSION}

The purposes of the TLFOB-USP are being reached in a gradual and satisfactory manner, which makes it important identify and repair the causes relative to the quitting of some participant members. Still, the importance of the involvement of the University in the development of projects that bring the students closer to the community once more was verified, which emphasizes their role in expanding the knowledge and improvement of the population's quality of life.

\section{REFERENCES}

1- Bashshur RL, Reardon TG, Shannon GW. Telemedicine: a new health care delivery system. Annu Rev Public Health. 2000;21:61337.

2- Cardoso RB, Huttner E, Hoppel A, Winter C, Huttner E, Celia S, et al. A successful telemedicine experience in the Brazilian Amazon Region. Acta Informatica Medica. 2007;15(4):211-5.

3- Chang BL, Trelease R. Education of professionals using a proposed telehealth system. Proc AMIA Symp. 1999:496-500.

4- Chao LW, Silveira PSP, Böhm GM. Telemedicine and education in Brasil. J Telemed Telecare. 1999;5(2):137-8.

5- Costaridou L, Panayiotakis G, Sakellaropoulos P, Cavouras D, Dimopoulos J. A network-based training environment: a medical image processing paradigm. Med Inform. 1998;23(4):277-87. 6- Doolittle GC, Spaulding RJ. Defining the needs of a telemedicine service. In: Wooton R, Craig J, Patterson V. Introduction to telemedicine. London: Royal Society of Medicine Press; 2006. p. 79-92.

7- Ferrari DV. Telessaúde: Acesso à educação e assistência em Audiologia. In. Bevilacqua MC, Martinez MAN, Balen SA, Pupo AA, Reis ACMB, Frota S. Saúde auditiva no Brasil: políticas, serviços e sistemas. São José dos Campos: Pulso Editorial; 2010. p. 189-218. 8- Finley JP, Beland MJ, Boutin C, Duncan WJ, Dyck JD, Hosking $M C$, et al. A national network for the tele-education of Canadian residents in pediatric cardiology. Cardiol Young. 2001;11:526-31. 9- Fraser HSF, McGrath JD. Information technology and telemedicine in sub-saharan Africa. BMJ. 2000;321(7259):465-6. 10- Jacobs J, Caudell T, Wilks D, Keep MF, Mitchell S, Buchanan H, et al. Integration of advanced technologies to enhance problembased learning over distance: Project TOUCH. Anat Rec B New Anat. $2003 ; 270(1): 16-22$.
11- Jaspers MW, Gardner RM, Gatewood LC, Haux R, Schmidt $D$, Wetter T. The International Partnership in Health Informatics Education. Stud Health Technol Inform. 2004;107(Pt 2)884-8.

12- Kesler C, Balch D. Development of a telemedicine and distance learning network in rural eastern North Carolina. J Telemed Telecare. 1995; 1(3):178-82.

13- Kirigia JM, Sambo LG, Phiri M, Matsembula G, Awases M. Cost-effectiveness analysis of establishing a distance education programme for health personnel in Swaziland. Afr ] Health Sci. 2002;9(1-2):3-15.

14- Kuchenbecker J, Dick HB, Schmitz K, Behrens-Baumann W. Use of internet technologies for data acquisition in large clinical trials. Telemed J E-Health. 2001;7(1):73-6.

15- Melo MCB, Magalhães Júnior HM, Santos AF, Souza C, Campos RT, Santos SF. Implantación del servicio de telesalud en el sistema público de Salud en Belo Horizonte - Brasil: ¿es posible reproducirlo? RevistaeSalud.com. 2007;3(9):1-14.

16- Melo MCB, Silva SEM. Aspectos conceituais em telessaúde. In: Santos AF, Souza C, Alves HJ, Santos SF, orgs. Telessaúde - Um instrumento de suporte assistencial e educação permanente. Belo Horizonte: Editora UFMG; 2006. p. 17-31.

17- Norris AC. Essentials of telemedicine and telecare. Baffins Lane: John Wiley \& Sons; 2002.

18- Riva G. From telehealth to e-health: internet and distributed virtual reality in health care. CyberPsych Behav. 2000;3(6):98998.

19- Ruiz JG, Mintzer MJ, Leipzig RM. The impact of e-learning in medical education. Acad Med. 2006;81(3):207-12.

20- Ruiz Ibañez C, Zuluaga de Cadena A, Trujillo Zea A. Telemedicina: introducción, aplicación y principios de desarrollo. CES Med. 2007;21(1):77-92.

21- Russomano T, Cardoso RB, Duval V, Lopes MH, Celia S, Hutter E. Space technology used to improve health care in remote areas. Aviat Space Environ Med. 2009;80:61-3.

22- Sood S, Mbarika V, Jugoo S, Dookhy R, Doarn CR, Prakash $\mathrm{N}$, et al. What is telemedicine? A collection of 104 peer-reviewed perspectives and theoretical underpinnings. Telemed J E Health. 2007;13(5):573-90.

23- Souza C, Melo MCB. Aspectos éticos e legais em telemedicina. In: Santos AF, Souza C, Alves HJ, Santos SF, orgs. Telessaúde um instrumento de suporte assistencial e educação permanente. Belo Horizonte: Editora UFMG; 2006. p. 32-45.

24- Spinardi ACP, Blasca WQ, De-Vitto LM. Genética e fonoaudiologia: aprendizado baseado na teleducação. Pró-Fono. 2008;20(Suppl):42-4.

25- Stanberry B. Telemedicine: barriers and opportunities in the 21st century. J Intern Med. 2000;247(6):615-28.

26- Thrall JH, Boland G. Telemedicine in practice. Semin Nucl Med. 1998;28(2):145-57.

27- Wen CL. Telemedicina - visão sob foco de uma disciplina. Rev Telem Telessaude. 2006;2(2):20-6.

28- Wen CL. Telemedicina e telessaúde - um panorama no Brasil. Informática Pública. 2008;10(2):7-15.

29- Wen, CL. Telessaúde - um instrumento de suporte assistencial e educação Ppermanente: telemedicina na Faculdade de Medicina da Universidade de São Paulo. Belo Horizonte: Editora UFMG; 2006. 